\title{
Benefits and Challenges of Resilience and Vulnerability for Disaster Risk Management
}

\author{
Alexander Fekete $\cdot$ Gabriele Hufschmidt • \\ Sylvia Kruse
}

Published online: 29 March 2014

(c) The Author(s) 2014. This article is published with open access at Springerlink.com

\begin{abstract}
This article addresses resilience and vulnerability as two prominent concepts within disaster risk science. The authors provide an overview of current uses and benefits of and challenges to resilience and vulnerability concepts for disaster risk management (DRM). The article summarizes the evolution of these concepts and of attempts to define them precisely, and addresses the potential benefits of conceptual vagueness. The usage and conception of resilience and vulnerability within a selection of strategies and legislations in DRM are compared. Complementing this analysis of disaster risk research and management practice, a survey identifies some of the benefits of and challenges to the concepts of resilience and vulnerability as seen by a peer-community. Synthesizing the three approaches, we conclude that a certain conceptual and methodological "haze" prevails, which hampers the transfer of information and findings within disaster risk science, from science to practice, and vice versa. But this vagueness offers opportunities for communication between disaster risk science, policy, and practice. Overall, evaluations of the resilience and vulnerability concepts are lacking, which demands the development of criteria to identify and assess the challenges to and benefits of resilience and vulnerability for DRM.
\end{abstract}

\footnotetext{
A. Fekete $(\square)$

Risk and Crisis Management Section, Cologne University of Applied Sciences, 50679 Cologne, Germany

e-mail: alexander.fekete@fh-koeln.de

G. Hufschmidt

Department of Geography, Master Program Disaster Management and Risk Governance, University of Bonn, 53115 Bonn, Germany

S. Kruse

Economics and Social Science, Swiss Federal Institute for Forest, Snow, and Landscape Research WSL, 8903 Birmensdorf, Switzerland
}

Keywords Boundary object · Disaster risk · Policy-science-practice interaction · Risk assessment $\cdot$ Resilience $\cdot$ Vulnerability

\section{Introduction}

The first phase of United Nations International Strategy for Disaster Risk Reduction (UNISDR)'s Hyogo Framework for Action (UNISDR 2005) will end in 2015, currently prompting considerations of how to proceed to effectively reduce disaster losses on a global scale. In retrospective, after several decades of discussion and application in the field of disaster risk management (DRM), it is time to recapitulate the benefits that the resilience and vulnerability concepts offer for DRM. Until now only a few peerreviewed articles have explicitly addressed the question of benefits and challenges relating to these concepts-that is, assessed their impacts, usefulness, and usability (Klein 2004; Ford et al. 2013). In many individual studies on DRM or climate change adaptation (CCA), the benefits of and challenges to these concepts for DRM are not discussed. Under the impression of extensive damage and loss suffered following yet another massive flood in Europe, we discuss the recent uses, benefits of, and challenges to the resilience and vulnerability concepts for disaster risk management.

Since definitions of resilience and vulnerability have been covered extensively elsewhere (Brand and Jax 2007; Lewis and Kelman 2010; Zhou et al. 2010; Bara and Brönnimann 2011; Garschagen 2013; Lorenz 2013), we cover the variability of definitions only briefly (Sect. 2). In this article, we use the term "resilience and vulnerability concepts" to refer to the whole range of resilience and 
vulnerability theories, frameworks, conceptual components, methods, and data that are used in DRM, as well as in disaster risk reduction (DRR) and CCA research and policy fields. Regarding the potential applications of resilience and vulnerability concepts, we mainly consider risk reduction measures, risk management plans and actions, and climate change adaptation measures in this article. We use "benefits" as a broad term encompassing ideas such as usefulness, improvement, or positive impacts. Under the term "challenges" we address limitations, problems, abuses, trade-offs, and other related terms. We understand disasters to be major instances of negative change, whether acute or gradual; disaster risk reflects the possibility of negative change; and disaster risk management describes the process of dealing with possible negative changes. We therefore use DRM as an umbrella term for the agenda used by multiple actors and defined in various ways. Companies, disaster and emergency authorities, media, NGOs, citizens, scientists, and many others have various capabilities and assets for handling disaster risks. We conceive DRM as embracing (1) all types of technological and "natural" hazards and risks, and (2) all phases of the temporal disaster cycle model (Alexander 2000, p. 3) both before and after disaster, as well as alternative conceptions of the disaster cycle (that is, spiral, evolutionary, and so on).

We approach our research question on the use of resilience and vulnerability concepts for DRM by summarizing in Sect. 2 how resilience and vulnerability are used as terms and concepts in disaster risk research. In Sect. 3, we investigate resilience and vulnerability as a policy field of DRM at different institutional levels. In Sect. 4, we gather the opinions of a peer-community of scholars and practitioners regarding the benefits of and challenges to the resilience and vulnerability concepts. Section 5 provides a summary of our findings and a discussion, while Sect. 6 offers a conclusion based on that discussion.

\section{Resilience and Vulnerability as Umbrella Terms for Disaster Risk Research}

Both resilience and vulnerability are concepts that have evolved in different disciplines and are applied in different fields of practice-disaster risk management being one of these fields. They have been in use for many decades, but there is no single precise definition of resilience and vulnerability. Though the advantages of precisely defined concepts for intradisciplinary research are evident, conceptual vagueness has some benefits for communication and for knowledge exchange across disciplinary boundaries and between the areas of science, policy, and practice. Building upon this insight, we first provide a summary of the concepts and attempts to gain precision in defining resilience and vulnerability, by relying on existing literature mainly from disaster risk sciences. We then elaborate the benefits of retaining some vagueness in the resilience and vulnerability concepts used in the interaction between science and practice in the field of DRM.

\subsection{Attempts to Define Resilience and Vulnerability}

Resilience, broadly defined as the capacity to resist and recover from loss, has developed as a central concept in disaster risk research in the last decades. The origin of the concept of resilience as used in disaster risk research is often attributed to the work of Holling, who applied the concept to social-ecological systems (Holling 1973). Nevertheless, the idea of resilience has been used in other disciplines, for example, psychology, engineering, for much longer (for the etymology and evolution of the concept, see Manyena 2006; Zhou et al. 2010; Alexander 2013; Park et al. 2013). Alexander recently traced back the use of the term resilience from Seneca the Elder, through Francis Bacon, to its first use in connection with disaster recovery by Tomes, after the earthquake in the city of Shimoda in Japan in 1854 (Alexander 2013, p. 2710). Parallel to this development, by the end of the nineteenth century the term resilience began to be used in mechanics and the evolving science of engineering, where it was connected with the terms robustness and ductility. Resilience also has appeared in psychology and medicine, where it was applied in studies with traumatized children to describe the capabilities of individuals under stress to maintain their psychological integrity and to adapt to circumstances produced by calamity (see Höfler in this issue). Holling applies the concept of resilience to ecological systems and in his oftencited article states that "resilience determines the resistance of relationships within a system and is a measure of the ability of these systems to absorb changes of state variables, driving variables, and parameters, and still persist" (Holling 1973, p. 17).

Although this is not the first application of the concept, Holling's work catalyzed a rapid growth in use of the term resilience in different fields of research after 1973 (Park et al. 2013). Its use expanded from systems ecology to other fields of research, including disaster risk research. Park et al. (2013) show that a recent rise of publications in the field of disaster management may be related to a series of natural and manmade disasters since the new millennium, which have been conceptualized using the resilience concept (for example, the Indian Ocean earthquake and tsunami in 2004, and Hurricanes Katrina and Rita in the Gulf of Mexico in 2005). After decades of resilience research and a rising body of literature applying this concept to disaster risk sciences, divergent definitions and 
highly varied methodological approaches exist (Zhou et al. 2010). The differences are connected to different epistemological approaches, which partly lead to fundamental conceptual differences and focuses of resilience.

Similarly to resilience, the concept of vulnerability has been applied to and elaborated in various disciplinary research domains ranging from hazard and disaster studies to geophysical sciences, human and political ecology, economics, and psychology, which has also led to fundamental conceptual differences (Miller et al. 2010). During the last 40 years it has become a core concept in disaster risk research (Burton et al. 1978; UNDRO 1982; Hewitt 1983, 1997; Watts and Bohle 1993; Blaikie et al. 1994; Oliver-Smith 1994, 2002; Anderson and Woodrow 1998; White et al. 2001; Cardona 2004; Wisner et al. 2004). Nevertheless, there is an ongoing debate on how to characterize vulnerability in both the theory and practice of disaster risk management (Birkmann 2006; Ionescu et al. 2009). Vulnerability is understood as a concept describing the differences in the degree of damage incurred from natural hazards that are manifested for an individual person, for a whole community, a city, or an entire region (Hufschmidt 2011). The various schools of thought that have elaborated on the concept of vulnerability focus on different conceptual elements of this concept, ranging from the direct outcome of a hazard to the influencing societal conditions, such as exposure, susceptibility, coping capacity, power relations, and social capital (Chambers 1989; Chambers and Conway 1992; Bohle et al. 1994; Wisner et al. 2004). Some scholars see advantage in the use of the concept of vulnerability in that it helps bridge different disciplinary perspectives and integrates biophysical, political, economic, and social factors that influence the degree of damage suffered (Cutter 1996; Mustafa et al. 2011).

Scholarly debates on resilience and vulnerability have developed independently of each other over decades, but there are a number of recent works that discuss the two concepts as interlinked (Cutter et al. 2008; Miller et al. 2010; Menoni et al. 2012). Some conceptualize resilience and vulnerability as subcomponents of each other (Turner et al. 2003), while others see one or both concepts as subcomponents of other umbrella terms, for example, risk (Cutter et al. 2008; Aven 2011). In the latter case scholars often subsume former terms such as adaptive capacity or coping capacity under the concept of resilience.

Regardless of the specific term or school of thought, recent meta-analyses of resilience and vulnerability concepts and methodologies have shown that there is often little coherence between the theoretical definitions and the methodologies applied in empirical studies (Ionescu et al. 2009; Miller et al. 2010; Hinkel 2011). Miller et al. (2010) not only state that there is a divide between theory and empirical application of the two concepts, but also emphasize that there is still a big gap between the ways in which these terms are understood and applied by academics, policy-makers, and practitioners. However, they see a difference between the implementation of the concepts of vulnerability and resilience: although vulnerability has long been incorporated into practice in disaster risk communities, there are only a few examples that document how resilience is explicitly incorporated into practice and policy.

Despite this conceptual blurriness and the difficulties in applying resilience and vulnerability, both concepts are used in disaster risk sciences. The EU-funded research project ENSURE, for example, has developed a resilience and vulnerability assessment framework and operational tool for natural and technical hazards (Menoni et al. 2012). The aim was to develop context-specific, indicator-based assessment tools that help the users to identify the strengths and fragilities of a given territory and community with respect to extreme natural events.

Park et al. (2013) develop a heuristic framework for a resilience analysis that is differentiable from, but complementary to, risk analysis for disaster management. They consider resilience as an outcome of a recursive process, and apply their framework to river flood management-without developing a clear methodology for resilience assessment. These recent examples show that there are some attempts to make resilience and vulnerability meaningful for disaster risk science and practice. Nevertheless, the criticism of Klein et al. (2003) still holds true: Rather than providing a definition and an explanation of an observable, measurable system attribute, resilience has become an umbrella concept with some normative appeal that leads to considerable confusion. Without an explicit operational definition, resilience has only a broad meaning, and remains a vague concept rather than a practical policy or management tool. Literature on vulnerability has grown and developed to a certain maturity level at which vulnerability has become a common evaluation feature of many risk assessments. In particular, these studies employ semi-quantitative vulnerability indices and geospatial assessments, as well as qualitative surveys and participatory approaches. While this specific research field and the number of applied vulnerability assessments are still expanding, the conceptual debates seem far from resolved.

We conclude that although the body of literature on vulnerability and resilience concepts has grown significantly during the last several decades, scholars still struggle to define the concepts, to relate them to each other, and place them in the context of disaster risk science. A shared understanding and definition of the concepts is still missing. 


\subsection{Resilience and Vulnerability as "Boundary Objects" for Disaster Risk Practice}

Both resilience and vulnerability are concepts that appear in a large body of literature, but the concepts remain, according to various scholars, "vague" (Strunz 2012), "metaphoric" (Norris et al. 2008), and "malleable" (Brand and Jax 2007). Nevertheless this vagueness could become an advantage when putting the concepts into practice in disaster risk management. Vogel et al. (2007) emphasize that the multidisciplinary nature of resilience and vulnerability research has to face linguistic, paradigmatic, theoretical, and methodological tensions. These tensions do not necessarily have negative impacts on the interaction between science and practice, but rather facilitate the coming together of different disciplinary scholars and practitioners from disaster research. Brand and Jax (2007) suggest that resilience has become a "boundary object" that facilitates communication across disciplinary borders by creating shared vocabulary, although the understanding of the parties may differ regarding their specific interpretation of the term in question. First described by Star and Griesemer (1989), boundary objects are both plastic enough to adapt to the local needs and constraints of several parties applying them and yet sufficiently robust to maintain a common identity for those applying them. If the boundary object remains open to interpretation, it can be highly useful as a communication tool in order to bridge scientific disciplines and the gap between scientific research, policy, and practice. In his argumentation from the point of view of philosophy of science, Strunz (2012) concludes that pragmatic and creative problem-solving may benefit from conceptual vagueness, which allows blurred conceptual boundaries as well as the use of metaphors. Miller et al. (2010) have also argued that resilience has colloquial and policy appeal for policy-makers and practitioners as it stresses positive and transformative processes, while vulnerability, when applied to label groups and regions, may be associated with a certain stigma. But as Klein (2009) points out, some (developing) countries may want to communicate their vulnerability in order to access adaptation funds.

\section{Resilience and Vulnerability in the Policy Field of Disaster Risk Management}

The guiding questions of this section are whether and how the concepts of resilience and vulnerability are applied in DRM strategies and policies. A range of examples is selected to cover legally non-binding and legally binding documents. Both, in particular legally binding documents, exert influence and pressure on DRM practice itself. Examples are provided that range from global through regional to national scales and focus on the European context.

\subsection{UNISDR}

Today, the United Nations International Strategy for Disaster Risk Reduction (UNISDR) is the focal point for the United Nations' policy-making and the coordination of preventive activities aimed at reducing disaster risks. The ISDR defines vulnerability as the susceptibility to the damaging effects of a hazard, and resilience as the ability to "resist, absorb, accommodate to and recover from the effects of a hazard in a timely and efficient manner". ${ }^{1}$ The ISDR, adopted in 1999, succeeds the United Nations' International Decade for Natural Disaster Reduction (IDNDR 1990-1999) (UN 1987). The IDNDR was criticized due to its initial focus on natural sciences and technology as "cures" for disasters (Mitchell 1990; Wisner 1993; Cardona 2004; UNISDR 2004). As the decade proceeded, a more holistic, people-centered perspective addressing socioeconomic vulnerability developed. ${ }^{2}$ The final declaration, the Geneva Mandate on Disaster Reduction adopted by the IDNDR program forum, is the founding document for the ISDR and underlines that "risk management and disaster reduction [must] become essential elements of government policies" (UN 1999, 16).

Five years later, following the World Disaster Reduction Conference in Kobe (Hyogo) in 2005, the UN General Assembly endorsed a 10-year plan, the Hyogo Framework for Action 2005-2015: Building the Resilience of Nations and Communities to Disasters (UN 2005). In order to achieve the overall goal of the Hyogo Framework for Action (HFA), namely the substantial reduction of disaster losses, three strategic goals are identified. At this strategic level the HFA reveals an imbalance between the concepts of vulnerability and resilience. While reducing vulnerability is one measure amongst others, building resilience is a strategic goal and "priority of action" itself. The HFA conceptualizes resilience as an overall desirable, yet by definition multifaceted and hence somewhat vague, condition. In contrast, vulnerability analysis and assessment are concrete tools and tasks of DRM, ${ }^{3}$ which includes risk analysis and mitigation practices as subsequent steps.

\footnotetext{
${ }^{1}$ http://www.unisdr.org/we/inform/terminology, based on the Glossary of 2009. Documents such as the UNISDR's Hyogo Framework for Action (UNISDR 2005) and the Mid-Term Review of the HFA (UNISDR 2010-2011) use a different definition.

2 Release of the Yokohama Strategy, World Conference on Natural Disaster Reduction 1994, and the strategy A Safer World in the Twenty-First Century: Risk and Disaster Reduction in 1999.

3 An extension of "risk management" indicating the context of disasters. http://www.unisdr.org/we/inform/terminology, based on the Glossary of 2009.
} 
Table 1 Summary of findings: the usage and conceptualization of resilience and vulnerability in selected legally non-binding and legally binding documents at the UN, the European, and the national European levels

\begin{tabular}{|c|c|c|c|}
\hline & \multicolumn{2}{|c|}{ Strategic goal } & \multirow{2}{*}{$\begin{array}{l}\text { Vulnerability as } \\
\text { a tool of analysis }\end{array}$} \\
\hline & $\begin{array}{l}\text { to build } \\
\text { resilience }\end{array}$ & $\begin{array}{l}\text { to reduce } \\
\text { vulnerability }\end{array}$ & \\
\hline \multicolumn{4}{|l|}{ Legally non-binding } \\
\hline UNISDR/HFA strategy & $X$ & - & $\mathrm{X}$ \\
\hline EU, security strategy & $\mathrm{X}$ & - & $-{ }^{\mathrm{b}}$ \\
\hline EU, climate change $(\mathrm{CC})$ strategy & $\mathrm{X}$ & - & $X$ \\
\hline Switzerland, strategy civil protection & - & - & $-{ }^{\mathrm{b}}$ \\
\hline Switzerland, strategy critical infrastructure & $\mathrm{X}$ & - & $X$ \\
\hline Germany, strategy civil protection & $-{ }^{\mathrm{a}}$ & - & $\mathrm{X}$ \\
\hline Germany, strategy climate change adaptation & - & $\mathrm{X}$ & $X$ \\
\hline UK, strategy civil protection & $\mathrm{X}$ & - & $-{ }^{b}$ \\
\hline \multicolumn{4}{|l|}{ Legally binding } \\
\hline EU, directive critical infrastructure & & & $\mathrm{X}$ \\
\hline EU, directive flooding & & & $-{ }^{\mathrm{b}}$ \\
\hline Switzerland, legislation civil protection & & & $-{ }^{\mathrm{b}}$ \\
\hline Germany, legislation civil protection & & & $-{ }^{\mathrm{b}}$ \\
\hline UK, legislation civil protection & & & $-{ }^{\mathrm{b}}$ \\
\hline
\end{tabular}

a Not explicit, "self-help" as one possible element of resilience

b Not explicit, as part of risk analysis?

At the UN-level, disaster risk management is regarded as part of DRR. Yet DRR is defined as a framework with the ultimate goal of building resilience (UNISDR 2012). UNISDR campaigns such as Making Cities Resilient: My city is Getting Ready ${ }^{4}$ and UNISDR documents, such as the Mid-Term Review of the HFA (UNISDR 2010-2011), and in particular the paper on a post-2015 framework (UNISDR 2012), mirror this conceptualization. What is more, the Fourth Session of the Global Platform for Disaster Risk Reduction in 2013 chose the motto "Resilient People, Resilient Planet" promoting in particular the resilience of communities while vulnerability is not addressed in certain key summaries (GPDRR 2013a, b).

The implementation of the UN General Assembly's resolutions, such as the ISDR and the HFA, are not legally binding for the UN member states. It is unclear whether a legally binding framework for DRR will follow the HFA (UNISDR 2012). Nevertheless, the ISDR and the HFA put pressure on national states to enact legislations, an approach that, according to the UNISDR, is meeting with success. However, it is difficult to judge the progress since documents such as the HFA Review 2007-2013 (UNISDR 2013) are based on voluntary self-assessment by the member states.

\footnotetext{
${ }^{4}$ See for example the list of essentials for making cities resilient, in particular, the injunction to "maintain up-to-date data on hazards and vulnerabilities, prepare risk assessments." http://www.unisdr.org/ campaign/resilientcities/toolkit/essentials.
}

In conclusion, the UNISDR conceptualizes resilience as an overall desirable condition, ultimate goal, and culture. Hence resilience is located at the top level of the strategic hierarchy. In contrast, vulnerability analysis, assessment, and reduction are placed on a lower level since they are included in a bundle of measures aiming to reach this ultimate goal of building resilient societies (Table 1).

\subsection{European Union}

At a regional level, the European Union (EU) approved the Internal Security Strategy for the European Union in March 2010 (European Council 2010). Terrorism, crime, general violence, and "natural and man-made disasters" are identified as major threats to the EU. An EU-wide risk analysis is envisaged as a basis of cooperation in the field of civil protection. The action plan adopted in November 2010 sets out more concrete objectives and accordant actions (EC 2010). One objective is to increase Europe's resilience to crisis and disasters with respect to all identified threats. EU-wide risk assessment and mapping guidelines based on a multi-hazard approach and national approaches to risk analysis and management are identified as corresponding actions. By 2014, a coherent EU risk management policy is expected to be established. The EU's strategic documents demonstrate that, similar to the UN objectives, resilience is regarded as the overall aim. Risk analysis, as an element of risk management, is included as 
a tool to facilitate this aim of a "resilient Europe." However, it remains unclear whether vulnerability analysis is regarded a part of risk analysis and management (Table 1).

In the following, three topics are selected from a range of key issues that Europe is considered to potentially face with respect to disaster risk. The first issue, critical infrastructure, is an example of a perspective that focuses on a specific object or "element at risk" rather than on a specific hazard. In comparison, the second example focuses on a specific hazard and its multiple adverse consequences for different objects and sectors. As a third example, this hazard (flood) is then placed in the context of climate change, which encompasses multiple hazards and multiple adverse consequences for multiple objects and sectors.

\subsubsection{Critical Infrastructure}

Within the context of "natural and man-made disasters" the EU addresses several issues by running special programs such as the European Programme for Critical Infrastructure Protection (EPCIP) (EC 2006). EPCIP and its preparatory Green Paper (EC 2005) provide strategy and policy options with the overall aim of protecting critical infrastructure. A complementary directive (EC 2008) transfers European law into national law and designates the procedure for assessing the need for critical infrastructure protection. This procedure includes the identification of critical infrastructure and the performance of risk analysis, that is analysis of threats, vulnerabilities, and potential impacts. Accordingly, EPCIP identifies the analysis and assessment of vulnerability as a necessity within the context of threat and risk analysis and assessment for critical infrastructure. Reducing vulnerability is defined as one work stream of EPCIP, which includes an analysis of appropriate protection measures. Used as a guideline, the Green Paper defines the terms "threat," "vulnerability," and "risk" according to an understanding in which risk is related to the probability of a potentially damaging event and its subsequent impact. Developing a common methodology for risk and vulnerability analysis is suggested (EC 2008). Implementation of EPCIP guidelines is optional for the member states. Nevertheless, as scheduled via the EU Commission's directive, member states must report on risks, threats, and vulnerabilities of critical infrastructure every 2 years. In the context of critical infrastructure, resilience is not used in these legally binding and legally non-binding documents. In comparison, vulnerability and the operationalization of vulnerability are prominent parts of this legislation.

\subsubsection{Flooding}

Another priority issue addressed on the EU level is flooding. The Directive on the Assessment and Management of
Flood Risks (EC 2007) was adopted in 2007. The EU flood directive is legally binding and must be implemented in national legislation. The EU directive defines risk as resulting from the interplay of the probability of a flood event occurring and the subsequent damages that may result. Member states are required to undertake preliminary flood risk assessments by the end of 2011, prepare flood hazard and flood risk maps by the end of 2013, and develop flood risk management plans by the end of 2015, with the latter including cost-benefit analysis. Neither resilience nor vulnerability are defined or implemented in this directive on flood risk management. An analysis of potential adverse consequences for human health, the environment, cultural heritage, and the economy is a legal requirement of this directive. But a differentiation of the degree of potential damage, and hence a vulnerability analysis, is not explicitly required.

\subsubsection{Climate Change Adaptation}

In recent years, the vulnerability and resilience assessment methodologies in both fields-DRM and CCA-have increasingly become more integrated (Birkmann et al. 2013). Because the CCA perspective specifically interconnects with DRM and is another top priority of the EU, the new EU Strategy on Adaptation to Climate Change (EC 2013) is addressed in this section. The goal of the strategy is to "contribute to a more climate-resilient Europe" (EC 2013, 5). Within the strategy, "adaptation" is the umbrella term used. A detailed definition of adaptation is not given, but the adaptation strategy includes a range of measures such as flood protection structures and "win-win, low-cost and no-regret adaptation options" such as early warning systems and sustainable water management (EC 2013, 5). Though in many respects imprecise, the strategy gives vulnerability as well as risk analysis a prominent and clearly defined role. The need for national risk assessment and management plans is underlined. The development of indicators for readiness, vulnerability, and adaptation efforts and the implementation of threat, vulnerability, and risk assessments are included in the strategy's action points. Resilience is not fleshed out in terms of specific measures. Rather, resilience is regarded as the overall aim and vaguely described "climate-resilient" products, services, investments, and economies are envisaged.

The EU strategy on adaptation to climate change is not legally binding. Nevertheless, tools and mechanisms for monitoring and evaluating the member states' progress are included in the strategy. The European Commission regards a legally binding document an option for 2017 in case progress needs to be reinforced. With respect to the legally non-binding regional EU strategy and the strategic CCA perspective, the approach of the UNISDR is echoed: 
resilience is the overall goal at the top level of the strategic hierarchy. In the context of CCA, vulnerability analysis is detailed within the methodological framework of risk management, with the aim of building a "climate-resilient Europe." In contrast, resilience does not play a role in the legally binding EPCIP and flood management directives. While EPCIP clearly includes consideration of vulnerability, the flood management directive does not incorporate vulnerability explicitly and remains vague with respect to assessing risk or the likelihood of "adverse consequences." So far, resilience is not included in legislation, but is prominent in strategic planning. The implementation of vulnerability in legislation differs (Table 1).

\subsection{National Civil Protection Strategies and Legislations}

In addition to the $\mathrm{UN}$ and $\mathrm{EU}$, three examples of national strategies and legislative acts are covered in this section. The selection does not deliver an all-encompassing analysis of national strategies and legislations in Europe, as this would exceed the scope of this article. Switzerland, Germany, and the United Kingdom are chosen as examples since they show similarities and differences regarding the application of resilience and vulnerability.

\subsubsection{Switzerland}

In 2012 Switzerland agreed on a Strategy for Civil Protection 2015+, which continues to include risk analysis in the portfolio of future tasks to be undertaken within the field of civil protection (SFC 2012a). In 2008, a national risk analysis was mandated to the Swiss Federal Office for Civil Protection (SFOCP) by the Swiss Federal Council. Hazards and potential damages based on damage indicators are analyzed periodically. Based on this analysis, an account of risks as an expression of the combination of the likelihood and extent of potential damage within the context of DRM is provided. Switzerland has an almost 20-year history of developing and applying a methodology for risk analysis (see Guideline KATANOS-Catastrophes and Emergencies in Switzerland. A Comparative Overview (SFOCP 1995); Guideline KATARISK-Catastrophes and Emergencies in Switzerland. A Risk Analysis from the Perspective of Civil Protection (SFOCP 2003)). Although the federal legislation-Federal Law on civil protection (BZG)_-does not include the requirement to conduct risk analyses on the Swiss canton level, 20 of the 26 cantons have conducted risk analyses within the last 10 years. Of those, 15 have enacted a political mandate in addition to or instead of a corresponding law, strengthening the implementation of risk analysis politically (Bara 2011). The guideline KATAPLAN (Cantonal Risk Analysis and
Prevention), developed by SFOCP (2013), has assisted the cantons in conducting their analysis since 2008. KATAPLAN starts by identifying threats, developing various scenarios according to different projected frequencies and magnitudes of these threats, and estimates their potential adverse consequences, hence risks. The results of the semiquantitative risk analysis are mapped as a coordinate within a risk matrix. The result of the damage analysis is a specific damage category adaptable to the cantonal context (for example, $30-100$ casualties, $10-30 \mathrm{~km}^{2}$ of damaged agricultural crop land). In order to define such clearly bounded damage classes, some degree of vulnerability analysis needs to be conducted. However, the vulnerability analysis is implicit rather than explicit and remains vague with respect to the methods used and the level of detail acquired. KATAPLAN does not address or implement the concept of resilience. In comparison, the National Strategy for the Protection of Critical Infrastructure (SFC 2012b) identifies resilience as the overall aim and vulnerability analysis as a tool for reaching this aim.

\subsubsection{Germany}

In Germany, the New Strategy for the Protection of the Population, first published in 2002, serves as a guideline for the advancement of civil protection (GFOCD 2010a). One of the key elements of the strategy is "self-help" 5 which is used in the sense of households' coping and dealing with crisis. In addition, a key element is agreement on specific protection targets based on risk analysis. The strategy follows an all-hazards approach. Of special interest is the federal law on civil protection and disaster assistance (ZSKG) (GFG 2009a), adopted in 2009. Its main purpose is to allow for more cooperation and sharing of resources between the Federation and the federal states. The ZSKG assigns the duty of promoting "self-help" to the municipalities/communities. What is more, the ZSKG instructs the Federation to conduct a nationwide risk analysis in cooperation with the federal states (GFG 2009a, § 18). The scenario-based, semi-quantitative methodology includes an estimation of the extent of potential damage associated with a specific hazard (GOFCD 2010b). The methodology is largely consistent with the Swiss approach as described above, but remains equally vague with respect to how the vulnerability analysis is carried out, and does not address resilience specifically. As compared to Switzerland, the methodology serves as a guideline and example for the federal states and municipalities. Below the national scale, flood risk analysis is compulsory for those regions potentially affected by floods as designated by the European Union legislation (Sect. 3.2.2), and is

\footnotetext{
5 In German, "Eigenvorsorge," "Selbstschutz," "Selbsthilfe."
} 
implemented in Germany by the Federal Water Act (GFG 2009b). In addition, federal states include flood risk analysis and management in their legislation. While vulnerability assessment guidelines exist for critical infrastructures (GFMI 2011) and community flood risk assessment (GFOCD 2010c), the application of those methodologies is optional and not explicitly described within the risk analysis guideline. Vulnerability reduction is the overall aim of the legally non-binding German Strategy for Adaptation to Climate Change (GFG 2008). A method for a federal vulnerability assessment is under development (Vetter and Schauser 2013).

There is still a lack of official documents at German national or regional levels that are using the term resilience, in contrast to countries such as Australia, the United Kingdom, and the United States. Also in certain expertise areas, resilience is only beginning to be discussed amongst policy makers and practitioners in Germany. ${ }^{6}$

\subsubsection{The United Kingdom}

The United Kingdom (UK)'s National Security Strategy was endorsed in 2010 and emphasizes the challenges faced in an "age of uncertainty" (UKG 2010). The strategy addresses the growing vulnerability of the country, and its strategic aim is to build a secure and resilient UK. Resilience is identified as the overall goal and is defined as the ability to recover quickly from disturbance, both on the national and local levels. Informing the public of risks is regarded as critical to promoting resilience (UKCO 2013). The UK's rationale behind promoting resilience is that some risks are regarded as unpredictable, and that the degree of uncertainty is so high that these risks cannot be prevented.

The underlying legislation adopted in 2004 is the Civil Contingencies Act (UKG 2004). This law requires the periodic analysis and assessment of multiple risks in order to plan for and to advise on risks on the local level. The understanding of risk in these requirements is based on an analysis of the likelihood and the potential damage of different threats. "Category 1 responders," that is, councils, emergency services, and appropriate bodies of the health and transport sectors, are obligated to conduct risk analyses and assessments based on a multi-hazard approach. The results are summarized in Community Risk Registers (CRR). CRRs must be maintained and published on each council's website. CRRs describe local hazards over a five-year period in combination with descriptions of related potential adverse consequences, such as damage and loss of lives.

\footnotetext{
${ }^{6}$ Expert Workshop of the Forschungsforum Öffentliche Sicherheit, 20-21 February 2013, Berlin on: Resilience-National Perspectives. http://www.sicherheit-forschung.de/news/13_03_12_ws_resilienz. html.
}

Subsequently risks are entered into a risk matrix comparable to the semi-quantitative Swiss and German methods. The creation of Local Resilience Forums (LRFs) is intended to guide and support the communities' risk analysis and assessment. On a national level, the governmental and confidential National Risk Assessment (NRA) identifies and monitors risks for the UK according to an all-hazards approach. A public version is the National Risk Register (NRR) (UKCO 2013) that was first published in 2008 and affirmed by the UK's National Security Strategy. Comparable to the guidelines of Switzerland and Germany, the UK's guidelines on risk analysis and assessment methodology are not specific enough to include vulnerability analysis explicitly in relation to these documents and tasks.

In summary, Switzerland and Germany identify resilience strategically in specific sectors such as critical infrastructure, but not as part of the overall goal for civil protection. With respect to legislation, both countries adopt risk analysis on the federal level with a history of additional activities in the Swiss cantons. Vulnerability analysis is not explicitly detailed in the corresponding methodological guidelines. Resilience is not included in the Swiss or German legislation. The latter may address resilience by including "self-help" in the German law (ZSKG). However, this association is questionable because it may narrow the conceptual depth of resilience that we find in psychology or social-ecological research. Compared to Switzerland and Germany, the UK incorporates resilience much more prominently on a strategic level, comparable with the UN's HFA, and the EU's strategy on adaptation to climate change. The implementation of Local Resilience Forums illustrates a shift from the national to the local scale, focusing on communities and individual residents. This shift is also described as "third/fourth wave" within the development of the UK's security (Omand 2013). Risk analysis and risk assessment are the methodological cornerstones of the UK's approach to resilience. But compared to Switzerland and Germany, the national and local levels are required by law to conduct risk analysis, and to maintain and publish CRR (Table 1).

\section{Peer-Community Survey on Benefits and Challenges of Resilience and Vulnerability}

This section presents the results of a small-scale survey amongst scientists and practitioners who attended a symposium organized by the "Katastrophennetzwerk KatNet," a German disaster network (KatNet 2012), which primarily contains participants from the German-speaking countries. The intention of the survey was to gather opinions on the benefits of and challenges to the resilience and vulnerability concepts as another source of opinion with which to 
complement our interpretations of scientific literature, strategies, and policies.

\subsection{Survey Design, Intention, and Limitations}

The survey was designed to allow quick responses, so as to avoid discouraging busy symposium participants. The survey covered nine questions, each with several specific answers that could be selected with a tick, but also with an unspecified category-Other (Please specify)—to allow answers outside those prescribed where necessary. We used an online survey tool that allowed for anonymity. Biases of which we are aware include the selection and specific contextual knowledge of this peer community as a sample. We also acknowledge limitations in the design of the questions, for example, those imposed by the use of shortened, sometimes vague, and predefined answer categories. Responses to the question about the benefits of using resilience and vulnerability for DRM were limited with regard to resilience, which might be due to a lack of familiarity on the part of survey participants with the concept. The low response frequency does not necessarily mean that this concept is less valid to the respondents than vulnerability. The qualitative responses in the tables are modified only by correcting obvious typos such as "difficult"; and by capitalizing the first letter in each phrase or sentence.

\subsection{Results and Discussion}

Of the 86 participants in the symposium, 38 attendees responded, the majority currently working as scientists (27), with five working as practitioners and six in other professions. Thirty-six respondents have working experience with vulnerability and 31 with resilience. The high response ratio of respondents to participants (38:86) is satisfying, and is probably due to this peer group being involved in and informed by the joint symposium half a year before.

\subsubsection{Reasons for Adopting the Term Resiliencel Vulnerability}

Most respondents gave as their reasons for the adoption of either resilience or vulnerability (Fig. 1) either science trend or necessary paradigm shift, followed by policy trend and new methods. Science trend was given as a reason for adopting the term resilience more often than it was for vulnerability. New measures to be implemented was given as a response more often in relation to vulnerability. Suggestion by a colleague received no responses for vulnerability and marketing received no responses for both resilience and vulnerability. Under the category other some respondents offered their own qualitative replies (Table 2; Fig. 2).

We interpret the responses as being in accord with our observations that the use of the concept of resilience is still a rather recent trend in both science and policy in Germany and its neighboring German-speaking countries. Not selecting marketing as a reason for the adoption of either term might reflect the science and non-profit backgrounds of most participants in the survey. But this could also be the result of an unclear question category or bad wording in the study design.

Some of the qualitative replies in Table 2 relate to the necessary paradigm shift, new methods, and policy trend answer categories. We interpret the qualitative answers to also reflect the differences between resilience and vulnerability. An important aspect is mentioned by the first quote (responses in the table appear in alphabetical order); to one
Fig. 1 Survey responses: reasons to adopt the term "resilience" or "vulnerability"

\section{What were the reasons for adopting resilience/ vulnerability (if applicable to you) and not another term?}

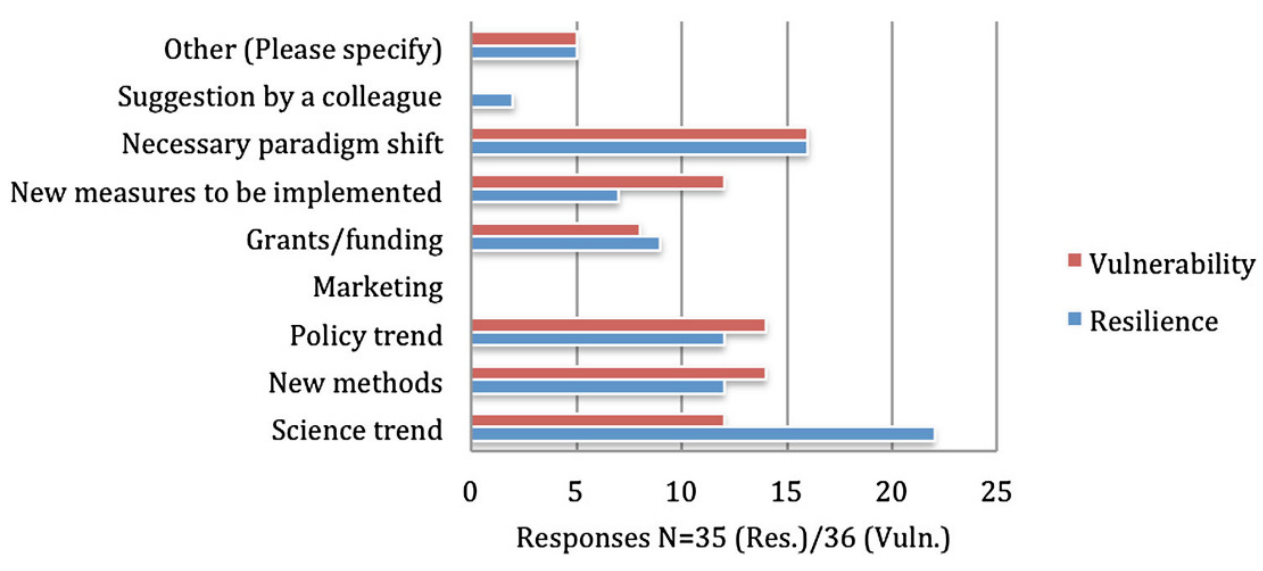


Table 2 Qualitative replies under the category "other," referring to the reasons for adopting the term resilience or vulnerability

Question 1: What were the reasons for adopting resilience (if applicable to you) and not another term?

Change of risk culture: Due to the lack of resources, we stopped fighting our vulnerability, we started to prepare for the "unexpected"

Heuristical value

(Lack of) Resilience was seen as part of our vulnerability framework

Own [re]search interest

Question 2: What were the reasons for adopting vulnerability (if applicable to you) and not another term?

Counterpart of resilience

Elaborated concept

Focus on social dimensions of disaster

In order to account for the negative consequence of a natural disaster

"Policy trend" in the sense that vulnerability assessments became important. Vulnerability is a well established term in science, engineering, and the DRR/DRM community

Strategic analyses

respondent, resilience means a change in "risk culture" from an emphasis on vulnerability to an emphasis on the capacity for preparation. In addition, for this respondent the idea of resilience is more connected to coping with unexpected events or processes. There are various usages for both terms, be they conceptual (including terminology) or methodological (heuristics or strategic analysis). These responses anticipated the next question in the survey.

\subsubsection{Benefits of Using the Term Resilience/Vulnerability for Disaster Risk Management}

Most respondents see the main benefits of using the term resilience/vulnerability for DRM as being conceptual/theoretical advancement. Methodological advancement is named more often as a benefit of using the term vulnerability, as are measurability and practical results and impact.

The responses show that the benefits of both concepts are largely seen in the conceptual/theoretical advancement of the field of DRM, closely followed by methodological advancement, in the case of vulnerability, and practical results and impact, with vulnerability slightly ahead of resilience. This might reflect a certain applicability or significance of impact attributed to both concepts. The low number of responses citing the measurability of resilience may echo the uncertainty in our peer community about the practical feasibility of semiquantitative approaches, sometimes termed "operationalization," although this is certainly also a big challenge for vulnerability assessments (also see Fekete 2012 and the short papers in this issue).

Some of the qualitative responses under the category "other" refer to the "trend" aspect in the previous questions, but most introduce new aspects not covered in the pre-defined answer categories. We interpret many descriptions to indicate typical demands from the policy and practitioner side; for example, awareness building, political compatibility, or practice.

Economic efficiency is not mentioned, but "target oriented" could be interpreted as relating to a certain organizational and strategic type of efficiency and feasibility. Strategic planning and the system connectivity in the last comment relate to a long-term perspective and in some sense to the evaluation criterion of sustainability.

\subsubsection{Main Problems and Challenges in Using the Term Resilience/Vulnerability for Disaster Risk Management}

Most respondents see the definition and the application/ operationalization of both concepts as the main challenges of using the term resilience/vulnerability for DRM (Fig. 3).
Fig. 2 Survey responses: benefits of resilience or vulnerability for disaster risk management

\section{What are the main benefits of using the term resilience/vulnerability for DRM?}

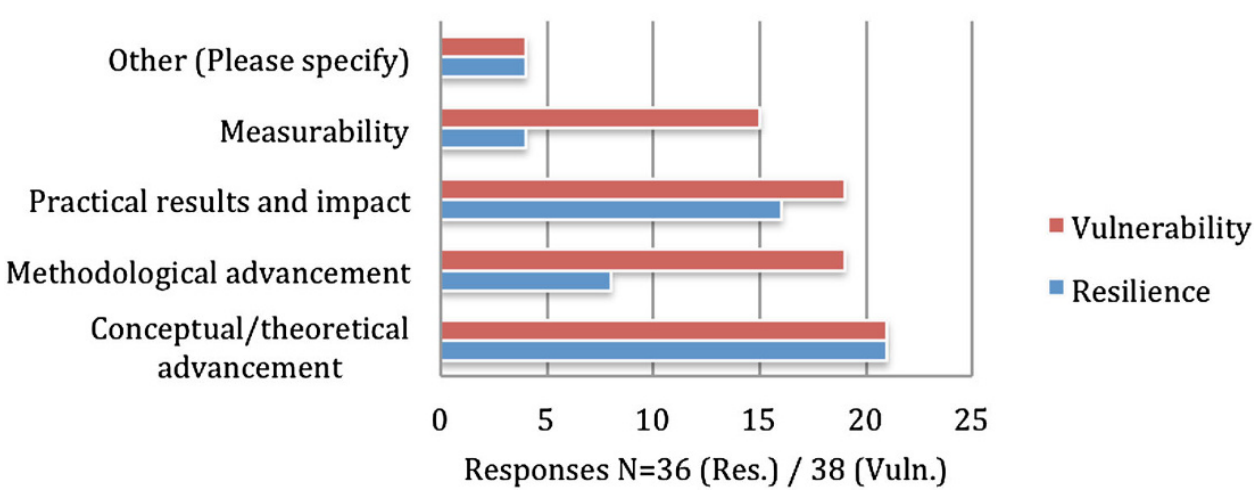


Fig. 3 Survey responses: main challenges to the use of resilience or vulnerability in disaster risk management

\section{What are the main problems and challenges of using the term resilience/vulnerability for DRM? ( $N=40)$}

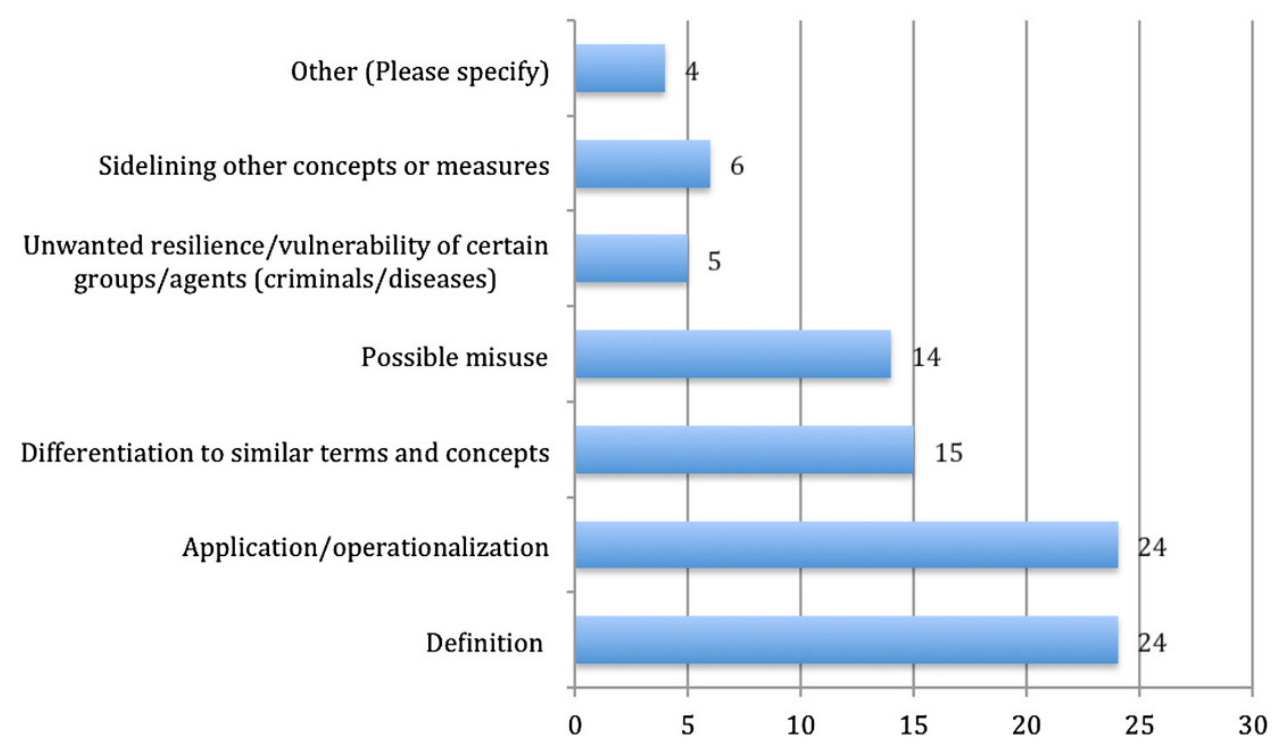

\section{Discussion}

concepts ${ }^{7}$ and possible misuse are also topics. Unwanted resilience or vulnerability of certain groups/agents such as criminals or diseases, and sidelining other concepts or measures are mentioned to a lesser degree.

We interpret the responses as indicating the continuing uncertainty about the clarification and definition of terminology, and thus of the challenges inherent in applying these terms. This is underlined by problems in the differentiation of resilience and vulnerability from similar terms and is explicitly evident from the high number of responses citing problems in their application. Overall this may reflect a certain lack of maturity of both these concepts in terms of established semantic standards, and may also suggest uneasiness about their measurability and direct implementation. The relatively high number of responses highlighting possible misuse of the concepts is notable. While other negative challenges, such as unwanted resilience or sidelining other concepts, are not ticked often, the community seems aware of some underlying critical aspects. We address the issues around unwanted resilience in more detail in the discussion section below.

The qualitative replies address challenges in communicating these concepts or in talking about them. We address these points in detail in the discussion section below.

\footnotetext{
7 In Fig. 3 we have presented the questions from the questionnaire with exactly the same wording as they had in the questionnaire itself. In the text beneath Fig. 3, we have quoted the questions as indicated in italic writing, except for "Differentiation to similar terms and concepts," since it was only in the language editing of this manuscript that it became apparent that in English this formulation is potentially ambiguous.
}

We have considered the usage of resilience and vulnerability and hinted at the benefits they offer and the challenges they face in science, strategies, and legislation. We have cast a spot-light on the various ideas about these benefits and challenges within the community of disaster risk scientists and practitioners. In this section, we summarize and discuss our findings, and also add further thoughts on resilience and vulnerability in disaster risk management.

\subsection{What is the Status Quo of Resilience and Vulnerability in Disaster Risk Management?}

In the following, our findings based on the scientific literature, strategies, legislations and the peer-community survey are summarized and discussed.

\subsubsection{Conceptual and Methodological Haziness}

The pluralistic character of disaster risk makes the variety of definitions, conceptions, and methods concerning resilience and vulnerability simultaneously necessary, confusing, and stimulating. The different conceptions of resilience and vulnerability pose a challenge for disaster risk science and practice. The literature review demonstrates that a shared understanding and definition of the two concepts is still lacking. As the results of the survey suggest (Question 5), such variety is problematic in terms of both defining the concepts themselves and differentiating them from similar terms and concepts. This imposes 
problems in the application and operationalization of resilience and vulnerability. This situation is less serious in the case of vulnerability, as reflected by the analysis of the strategic and legislative documents and the results of our survey (Questions 2 and 4).

Hence, we see the need and potential for harmonization. Conceptual and methodological variety and haziness are intrinsic to disaster risk science and management. Vagueness offers benefits for interdisciplinary and science-practice interaction. The very conceptual variation and vagueness of vulnerability and, in particular, resilience may facilitate their use as communicative bridges between scholars and practitioners from different disciplines in disaster risk management. Such "boundary objects" facilitate communication across disciplinary borders and bridge the gap between science, policy, and practice. Some have argued that resilience has colloquial and policy appeal as it stresses positive and transformative processes. From a political-strategic perspective, resilience is well established at the top level of the strategic hierarchy and is identified as a desirable condition, overall aim, and cultural attribute, as for example is demonstrated by the UN's HFA, the EU strategy for adaptation to climate change, and the UK's civil protection strategy. ${ }^{8}$ Interestingly, the participants in our survey rated vulnerability as slightly more visible than resilience with respect to a policy trend. But one respondent affirmed resilience as being politically compatible, target-oriented, and positively connoted (Question 3). Since resilience is associated with a positive condition, from a political-strategic perspective the concept serves to assemble different stakeholders with different interests behind one goal: that of reducing the negative impacts of disasters.

In our view the literature and strategies included here clearly show that resilience is used as an umbrella term. If these efforts are channeled towards mobilizing resources and political will with the overall aim of increasing the knowledge base about disaster risk, we believe that end justifies the means. However, we see a danger that the scientific concept and the conceptual advancement of resilience suffer from such usage, since resilience is dismissed as only a buzzword. Already some experts regard resilience merely as a fashion, metaphor, analogy, marketing term, or paradigm (Dombrowsky 2013). The "myth" (Kuhlicke 2013), "catchword," and "science and policy trend" aspects of resilience meet problems when theory is put into practice. But use of resilience does

\footnotetext{
8 This is also the case for numerous organizations we have not covered in this article. For example, resilience is also regarded an "excellent rallying point to connect the different policy communities working on different types of risks. Resilience as a common goal has the potential to bring together humanitarians, stabilization and development actors" (OECD 2013, p. 1).
}

instigate critical discussion and communication about risks, which we see as beneficial for the advancement of DRM.

\subsubsection{Vulnerability and Risk Analysis in Disaster Risk Management}

Although the vulnerability concept is still characterized by a considerable degree of conceptual variation and haziness, the literature review and the survey (Questions 2 and 4), show that compared to resilience the vulnerability concept is more elaborated and advanced methodologically. This is mirrored by the usage of vulnerability in strategic documents in the fields of DRM, DRR, and CCA. Within the UNISDR framework, in particular in the HFA, vulnerability analysis and assessment are established as risk analysis tools. This approach is reflected by the EU's strategy on adaptation to climate change and the EPCIP, which are transferred into legislation. Although there is no standard procedure for analyzing vulnerability, the use of vulnerability is widely accepted and requested. Because risk analysis also varies methodologically, there is a common understanding that an estimation of the degree of potential losses is necessary. This occurs because a hazard of a given magnitude may have completely different consequences depending on the vulnerability of the system that is affected. Consequently, risk analysis is needed to plan preventive measures and is a precondition for communicating risks. In this context, vulnerability is the key to analyzing risks and understanding disasters.

\subsubsection{Beyond Risk Analysis: Resilience, Vulnerability, and the Unexpected}

How do we prepare for the unexpected? In our highly interconnected, complex world systemic risks often include "domino effects" (Renn et al. 2007; Renn and Keil 2008, 2009). In such complex systems, the conjunction of (smallscale) mistakes or failures can lead to a catastrophe (Perrow 1984). Weick and Sutcliffe (2007) have analyzed highreliability organizations that must continue to function because their failure will result in fatal losses. They suggest building up resilience, in the sense of increasing these organizations' capacities and flexibility, as one means of disaster prevention. The concept of resilience offers a perspective that includes the possibility of risks beyond those that we can identify and analyze with a risk analysis toolbox. The UK follows this perspective. The pursuit of resilience is adopted based on the consideration that some risks are unpredictable and that uncertainty remains an intrinsic element of society. Hence resilience of communities is considered beneficial for dealing with impacts yet not known. This view is also present in our survey (qualitative answer to Question 1), supported by a conviction 
that resources are scarce, which requires a decision regarding the channeling of resources to specific ends. We maintain that the concept of resilience can offer an answer to the question of how to prepare for the unexpected. But we also believe that reducing vulnerability also offers real potential in a resource-constrained world. Reducing vulnerability is beneficial when facing the unexpected, since the degree of damage will be less. In addition, scholars conceptualize resilience and vulnerability as highly interconnected concepts, or even as elements of each other. From this perspective a divide would not be meaningful.

\subsubsection{Transfer of Political Mandates into Practice}

Some countries, such as Switzerland and Germany, have incorporated risk analysis on a national level into their legal system, and the UK has enacted risk analysis at both the national and local level. But except for the case of EPCIP, vulnerability analysis is included implicitly rather than explicitly in the legislation reviewed in this article. Vague descriptors such as "damage assessment" or the "estimation of adverse consequences" are preferred and explicit adaptations are not detailed. Legal requirements provide added impetus to disaster risk management and foster comprehensive action. Political will and legislative enforcement are crucial for stronger disaster prevention, as stated by the UNISDR. However, legislation tends not to address vulnerability explicitly. Corresponding methodological guidelines leave much scope for the transfer of concepts into practice, as illustrated by the EU flood directive: member states are requested to use the best practice and best technologies available for their risk maps and risk management plans, while excessive costs ought to be avoided. In Switzerland, Germany, and the UK vulnerability analysis remains blurry with respect to methods and data used and level of detail required. These decisions need to be made by the practitioners, that is, the disaster risk managers. Considering the limited financial resources available for the acquisition of skills, technologies, and data, legislation in support of DRM will likely continue to leave much room for interpretation as to whether and how vulnerability analysis is integrated into DRM. While the reasons for such vagueness are understandable, if risk analysis is a legal requirement, vulnerability analysis should be clearly addressed, as it is in EPCIP. It is then vital to provide resources to assist the integration of vulnerability reduction into the different scales of disaster risk management.

\subsubsection{Transfer of Responsibility to Citizens Mainly}

Resilience may be used to justify a hidden transfer of responsibility from public authorities to citizens. This argument is exemplified by the UK example, which strongly promotes local resilience. We identify this issue as a challenge to working with the resilience concept. Dombrowsky (2013) observes a loss of the original meaning of resilience, and the misuse of the term when public authorities promote the increased "resilience of communities" and the transfer of responsibility to the citizens under the banner of "building resilient communities." $\mathrm{He}$ questions whether this understanding and use of the term is meaningful in the face of conceivable extreme events, such as a nuclear disaster or the presence of toxic substances in our daily food. Dombrowsky would prefer that resilience is understood as making citizens more critical and resistant to being exposed to such hazards in the first place.

While this view rightly pinpoints a possible misuse of the term by public authorities seeking to retreat from responsibility, the present pressures on civil protection structures need to be considered. Risk potential is rising. On the one hand we possibly face a more frequent occurrence of extreme events; we live in a highly globalized and interconnected world that imports and exports risks (for example, infectious diseases), and we are highly dependent on critical infrastructures that are tightly interconnected and exposed. Conversely, we observe a rising shortage of financial resources, personnel, and volunteers in DRM; when disaster happens, public authorities will not be able to prevent losses and disruptions. Building resilience is indeed an important measure of disaster prevention. This requires clearly defined concepts and plans for concrete measures to be implemented. In addition, despite all our scanning of the risk horizon and the use of think tanks in the attempt to anticipate the unexpected, it is very likely that we will miss a range of systemic risks. To build resilience at all levels entails fostering preparedness in case the unexpected becomes reality. When considering the context of the HFA, "building resilient communities" is crucial in countries where public authorities are weak, are not trustworthy, or have no resources for DRM. Strengthening the local capacity of people under these circumstances is vital indeed.

\subsection{Where to Go from Here? Discussion of Future Research Needs}

In addition to the results and findings presented so far, in the following we add some further thoughts on the requirements for future research concerning the benefits of and challenges to resilience and vulnerability for disaster risk management.

\subsubsection{Pitfalls of Resilience and Vulnerability}

Our discussion of challenges has shown potential problems associated with a political use, or misuse, of the concept of 
resilience. Widely absent is even an awareness, let alone a thorough scientific analysis of, the possible pitfalls of the use of resilience and potential types of what might be termed "mal-resilience," in analogy to "mal-adaptation." For instance, "bouncing back" in the sense of rebuilding preexisting vulnerable conditions, or by resettlement of poor people in flood-prone areas, has been extensively covered (Oliver-Smith 1991; Fernando 2010). Another aspect of mal-resilience might take the form of hidden agendas behind the façade of resilience; a very real possibility the prospect 'that the 'myth of resilience' may become a powerful worldview that enables actors to define what is 'right' and what is 'wrong'"(Kuhlicke 2013, p. 61). Other potential downsides of the overly positive advocacy of uncontrolled and self-serving shortsighted development and innovation are issues that still need to be researched as potential forms of mal-resilience. Even the way in which resilience is conceptualized involves trade-offs; for instance, deciding between proactive and reactive resilience (Frommer 2013). Another challenge to the use of resilience is the possibility that its use may sidelining previous approaches such as vulnerability assessment (Hufschmidt 2011; Deeming 2013). Beyond that, even unwanted forms of resilience exist, for example persistent structural systemic conditions such as corruption or marginalization that are often discussed within social vulnerability or community resilience research. Other unwanted forms of resilience are those displayed by terrorist or criminal groups or disease-causing microorganisms (Zolli and Healy 2012). In previous work on vulnerability, we have identified pitfalls in the methods used to develop vulnerability indices and obtain data, as well as in the communication with end users, and the stigmatization and victimization of the vulnerable (Hufschmidt 2011; Fekete 2012). One of the biggest challenges encountered is trying to apply and "operationalize" the terminology and theoretical concept of vulnerability, which is also reflected by the replies to Question 5 (Fig. 3). Some of our lessons learned might be helpful for resilience research and practice, but it seems that resilience brings another set of challenges to the table (Tables 3,4).

\subsubsection{Evaluation Criteria for Benefits}

Reports, for instance by the International Federation of Red Cross and Red Crescent Societies (IFRC 2012), provide detailed information about the general impacts and benefits of resilience and vulnerability. However, it is difficult to see how this can be specifically related to DRM or DRR. Within the context of CCA, Vetter and Schauser (2013) analyze which criteria would be useful for prioritizing adaptation measures and opt to include "acceptance" as a criterion. Gathering evaluation criteria to estimate the benefits of
Table 3 Qualitative replies under the category "other," regarding the benefits of resilience or vulnerability for disaster risk management

Question 3: What are the main benefits of using the term resilience for DRM?

To extract the characteristics of the development of understanding security and one might mark differences in educational aspects

Awareness building expansion to non-physical topics

Is the new term

Political compatibility; target oriented \& positively connotated To describe certain measures

Question 4: What are the main benefits of using the term vulnerability for DRM?

To extract the characteristics of the development of understanding security and one might mark differences in educational aspects

Awareness building expansion to non-physical topics

For practice: strategic planning

Possibility to connect environment, infrastructure \& society systemically

Table 4 Qualitative replies under the category "other" with regard to the problems and challenges in the use of resilience or vulnerability for disaster risk management

Question 5: What are the main problems and challenges of using the term resilience/vulnerability for DRM?

Difficult to explain to non-scientific project partners

In edu: soldiers mentality; disaster control: it is a view aggregating elements and relations instead of distinguishing

Interdisciplinary teams require the awareness that there can be different definitions; Difficulty to find the same "language" or at least to understand another "language"

The duality to efficiency (operational financial concepts) for political decision-making processes.

resilience and vulnerability is the task of an ongoing research project at the Cologne University of Applied Sciences; the topic involves an international comparison of the benefits of critical infrastructure research projects for civil protection (Project name: KritisFuE). As a preliminary result, evaluation criteria are broad and diverse enough to include accessibility, efficiency (also: effectivity, efficacy), feasibility, impact, improvement, novelty, relevance (for a certain usergroup or agenda), simplicity, and sustainability. This wide range of evaluation criteria illustrates how difficult it is to evaluate any project or theme. The evaluation of resilience and vulnerability is aggravated by the multifaceted attributions both concepts have accumulated over the years in different disciplines.

In fact it is difficult to actually depict the effectiveness of measures for reducing vulnerability and increasing resilience, which would finally reduce damage and risk. This is because the comparability of disasters is low; it is 
rare that the same type of disastrous event recurs, especially in the same place, because changes occur in the overall setting (new buildings, different mix of population, and so on). One such rare example is the flooding of the Rhine, which occurred in 1993 and again in 1995. In 1993, with the Rhine reaching $10.63 \mathrm{~m}$ in Cologne, the damage done amounted to approximately USD 87 million. In 1995, a flood reaching $10.69 \mathrm{~m}$ resulted in total damages of only USD 37 million; this is less than $50 \%$ of the cost encountered 2 years previously (Fuchs and Vogt 2013). Better or more extensive flood protection structures had not at that time been realized by the city's public authority. Rather, this drastic reduction of damage can be attributed to effective communication and support between the residents, and between the residents and the City of Cologne's Flood Protection Center (FPC Cologne) as the public authority in charge. Residents and local businesses reflected on the damage mechanisms and implemented straightforward measures such as securing buildings and underground parking areas against floods (Fuchs and Vogt 2013). It is difficult to assign the various measures that have been realized to strict vulnerability-reducing or resilience-increasing categories. The main point is that damage was reduced very effectively through a process of learning and communication followed by implementation of suitable measures. While this example illustrates the monetary benefit of resilience and vulnerability measures, the implications of resilience and vulnerability need to be evaluated beyond simple economic indicators, even when policy makers and the industry may respond more to economic evidence, compensation demands, or legal liability.

\section{Conclusion}

The HFA will come to an end in 2015. Consultations on how to proceed are currently ongoing. The HFA and the ISDR promote resilience as an overall goal and a cultural attribute to which to aspire. We find vulnerability and vulnerability analysis subordinated to the roles of tools for DRR, which ultimately aims to "build resilience." Considering that vulnerability studies have a much longer tradition in disaster risk science and management, this development is noteworthy. With vulnerability and resilience currently being discussed on the international policy agenda, a reflection on the usage, benefits, and challenges of resilience and vulnerability is timely. Using literature sources, strategies, and legal documents, supported by a small survey among a peer group, we have identified some of the multiple benefits of and challenges to resilience and vulnerability, aiming to address both concepts equally.

Looking ahead, we see relevance for platforms such as the HFA in promoting the advancement and improvement of the concepts of resilience and vulnerability in terms of their benefits, challenges, possible pitfalls, and misapplications. There remains a need for more in-depth scientific evaluation studies in this field. While evaluation studies and criteria for NGOs and project reporting to donor agencies exist, there is a paucity of evaluation criteria in scientific papers. We also need a more systematic and rigid evaluation of the benefits and challenges once measures for reducing vulnerability and increasing resilience are in place. Such evaluation would require mid- and long-term studies with an appropriate level of funding. We see major potential benefits of both concepts due to their stimulation of interdisciplinarity that bridges science, policy, and practice, and due to their potential for improvement in effectively reducing disaster risks within the practical field of disaster risk management. This requires considerable effort, boldness, and closer cooperation between science, policy, and practice. Finally, we stress the need for a more reflective and careful use of both terms, in particular of resilience.

Acknowledgments We are grateful to the participants of the symposium "Resilience and Vulnerability-What is the Usage of these Concepts for Disaster Management?" organized by the disaster network KatNet in November 2012 at the University of Bonn, Germany, for the inspiring discussions that led in part to the writing of this article. We would very much like to thank all those participants of the symposium who took part in our survey. Our gratitude goes also to Christiane Grinda for helpful comments on a draft version, and finally to the external reviewers for taking the time and effort to help us improve our paper.

Open Access This article is distributed under the terms of the Creative Commons Attribution License which permits any use, distribution, and reproduction in any medium, provided the original author(s) and the source are credited.

\section{References}

Alexander, D.E. 2013. Resilience and disaster risk reduction: An etymological journey. Natural Hazards and Earth System Sciences 13(11): 2707-2716.

Alexander, D.E. 2000. Confronting catastrophe. New York: Oxford University Press.

Anderson, M.B., and P.J. Woodrow. 1998. Rising from the ashes: Development strategies in times of disaster. Boulder: Lynne Rienner.

Aven, T. 2011. On some recent definitions and analysis frameworks for risk, vulnerability, and resilience. Risk Analysis 31(4): $515-522$.

Bara, C. 2011. Risk analysis in civil protection (Risiko-und Gefährdungsanalysen im Bevölkerungsschutz). Zurich: Center for Security Studies (CSS), Eidgenössische Technische Hochschule.

Bara, C., and G. Brönnimann. 2011. Focal report 6. Risk analysis. resilience-Trends in policy and research. Zurich: Crisis and Risk Network (CRN), Center for Security Studies (CSS), Eidgenössische Technische Hochschule. 
Birkmann, J. (Ed.) 2006. Measuring vulnerability to natural hazards: Towards disaster resilient societies. Tokyo: United Nations University Press.

Birkmann, J., O.D. Cardona, M.L. Carreño, A.H. Barbat, M. Pelling, S. Schneiderbauer, S. Kienberger, M. Keiler, et al. 2013. Framing vulnerability, risk and societal responses: The move framework. Natural Hazards 67(2): 193-211.

Blaikie, P., T. Cannon, I. Davis, and B. Wisner. 1994. At risknatural hazards, people's vulnerability and disasters, 2nd ed. London: Routledge.

Bohle, H.G., T.E. Downing, and M.J. Watts. 1994. Climate change and social vulnerability: Toward a sociology and geography of food insecurity. Global Environmental Change 4(1): 37-48.

Brand, F. S., and K. Jax. 2007. Focusing the meaning(s) of resilience: Resilience as a descriptive concept and a boundary object. Ecology and Society 12(1): Article 23.

Burton, I., R. W. Kates, and G. F. White. 1978. The environment as hazard. 2nd ed. 1993. New York: The Guilford Press.

Cardona, O.D. 2004. The need for rethinking the concepts of vulnerability and risk from a holistic perspective: A necessary review and criticism for effective risk management. In Mapping vulnerability -Disasters, development and people, ed. G. Bankoff, G. Frerks, and D. Hilhorst, 37-51. London: Earthscan.

Chambers, R. 1989. Vulnerability: How the poor cope. IDS Bulletin 20(2): 1-7.

Chambers, R., and G.R. Conway. 1992. Sustainable rural livelihoods: Practical concepts for the 21th century. Brighton: Institute for Development Studies, University of Sussex.

Cutter, S.L. 1996. Vulnerability to environmental hazards. Progress in Human Geography 20(4): 529-539.

Cutter, S.L., L. Barnes, M. Berry, C. Burton, E. Evans, E. Tate, and J. Webb. 2008. A place-based model for understanding community resilience to natural disasters. Global Environmental Change 18(4): 598-606.

Deeming, H. 2013. Clarifying resilience: An invited comment. Natural Hazards Observer 37(1): 14-16.

Dombrowsky, W. 2013. Resilience-Progress or ideology? (Resilienz-Fortschritt Oder Ideologie?) Notfallvorsorge 1: 22-26.

EC (European Commission). 2005. Green paper on a European programme for critical infrastructure protection. $\mathrm{COM}(2005)$ 576 final. Brussels. http://eur-lex.europa.eu/LexUriServ/site/en/ com/2005/com2005_0576en01.pdf.

EC (European Commission). 2006. Communication from the commission on a European programme for critical infrastructure protection. $\operatorname{COM}(2006) 786$ final. Brussels. http://eur-lex.europa. eu/LexUriServ/site/en/com/2006/com2006_0786en01.pdf. Accessed 18 March 2014.

EC (European Commission). 2007. Directive on the assessment and management of flood risks. 2007/60/EC. Brussels. http://eur-lex. europa.eu/LexUriServ/LexUriServ.do?uri=OJ:L:2007:288:0027: 0034:en:pdf. Accessed 18 March 2014.

EC (European Commission). 2008. Directive on the identification and designation of European critical infrastructures and the assessment of the need to improve their protection. Brussels. 2008/114/ EC. http://eur-lex.europa.eu/LexUriServ/LexUriServ.do?uri=OJ: L:2008:345:0075:0082:EN:PDF. Accessed 18 March 2014.

EC (European Commission). 2010. The EU internal security strategy in action: Five steps towards a more secure europe. $\operatorname{COM}(2010)$ 673 final. Brussels. http://europa.eu/legislation_summaries/jus tice_freedom_security/fight_against_organised_crime/j10050_en. htm. Accessed 18 March 2014.

EC (European Commission). 2013. EU strategy on adaptation to climate change. $\operatorname{COM}(2013) 216$ final. Brussels. http://eur-lex. europa.eu/LexUriServ/LexUriServ.do?uri=CELEX:DKEY=7255 22:EN:NOT. Accessed 18 March 2014
European Council. 2010. Draft internal security strategy for the European Union: "Towards a European security model." 7120/10. Brussels: European Council.

Fekete, A. 2012. Spatial disaster vulnerability and risk assessments: Challenges in their quality and acceptance. Natural Hazards 61(3): 1161-1178.

Fernando, N. 2010. Forced relocation after the Indian Ocean tsunami, 2004. Case study of vulnerable populations in three relocation settlements in Galle, Sri Lanka. Dissertation, University of Bonn.

Ford, J.D., M. Knight, and T. Pearce. 2013. Assessing the "usability" of climate change research for decision-making: A case study of the Canadian International Polar Year. Global Environmental Change 23: 1317-1326.

Frommer, B. 2013. Climate change and the resilient society: Utopia or realistic option for German regions? Natural Hazards 67(1): 99-115.

Fuchs, G., and R. Vogt. 2013. Personal communication. Flood Protection Center, Cologne. May 2013.

Garschagen, M. 2013. Resilience and organisational institutionalism from a cross-cultural perspective: An exploration based on urban climate change adaptation in Vietnam. Natural Hazards 67(1): 25-46.

GFMI (Germany, Federal Ministry of the Interior [Bundesministerium des Innern]). 2011. Protecting Critical Infrastructures - Risk and Crisis Management: A Guide for Companies and Government Authorities (Schutz, Kritischer Infrastrukturen - Risiko- und Krisenmanagement. Leitfaden für Behörden und Unternehmen). Berlin: BMI (in German).

GFG (German Federal Government [Bundesregierung der Bundesrepublik Deutschland]). 2008. German Strategy for Adaptation to Climate Change (Deutsche Anpassungsstrategie an den Klimawandel). http://www.bmub.bund.de/en/topics/climate-energy/cli mate/details-climate/artikel/deutsche-anpassungsstrategie-an-denklimawandel/?tx_ttnews[swords]=climate\&tx_ttnews[backPid]= 921\&cHash $=1 \mathrm{e} 22204 \mathrm{c} 8 \mathrm{c} 1369 \mathrm{~b} 5596 \mathrm{f} 84 \mathrm{~d} 8 \mathrm{f} 866 \mathrm{f} 298$ (in German). Accessed 18 March 2014.

GFG (German Federal Government [Bundesregierung der Bundesrepublik Deutschland]). 2009a. Federal Law on Civil Protection and Disaster Assistance (Gesetz über den Zivilschutz und die Katastrophenhilfe des Bundes-ZSKG). http://www.juris.de/purl/ gesetze/_ges/ZSG (in German). Accessed 18 March 2014.

GFG (German Federal Government [Bundesregierung der Bundesrepublik Deutschland]). 2009b. Federal Water Act (Gesetz zur Ordnung des Wasserhaushalts - WHG). http://www.juris.de/ purl/gesetze/WHG (in German). Accessed 18 March 2014.

GFOCD (Germany, Federal Office of Civil Protection and Disaster Assistance [Bundesamt für Bevölkerungsshutz und Katastrophenhilfe]). 2010a. New Strategy for the Protection of the Population in Germany (Neue Strategie zum Schutz der Bevölkerung in Deutschland). In Wissenschaftsforum 4. Bonn: GFOCD. http://www.bbk.bund.de/SharedDocs/Kurzmeldungen/ BBK/DE/2011/18011300_Publikation_Neue_Strategie_2_Auflg. html (in German). Accessed 18 March 2014.

GFOCD (Germany, Federal Office of Civil Protection and Disaster Assistance [Bundesamt für Bevölkerungsshutz und Katastrophenhilfe]). 2010b. Method for Risk Analysis in Civil Protection (Methode für die Risikoanalyse im Bevölkerungsschutz). In Wissenschaftsforum 8. Bonn: GFOCD. http://www. bbk.bund.de/SharedDocs/Downloads/BBK/DE/Publikationen/Wis senschaftsforum/Bd8_Methode-Risikoanalyse-BS.html (in German). Accessed 18 March 2014.

GFOCD (Germany, Federal Office of Civil Protection and Disaster Assistance [Bundesamt für Bevölkerungsshutz und Katastrophenhilfe]). 2010c. Estimating Vulnerability of Municipalities in the Case of Floods (Abschätzung der Verwundbarkeit gegenüber Hochwasserereignissen auf kommunaler Ebene). 
Bonn: GFOCD. http://www.bbk.bund.de/SharedDocs/Downloads/ BBK/DE/Publikationen/Praxis_Bevoelkerungsschutz/Band_4_ Praxis_BS_Hochwasser-Kommuna-Ebene.html (in German). Accessed 18 March 2014.

GPDRR (Global Platform for Disaster Risk Reduction). 2013a. Chair's Summary. Fourth session of the global platform for disaster risk reduction. Geneva. http://www.ifrc.org/docs/IDRL/ 33306_finalchairssummaryoffourthsessionof.pdf. Accessed 21-23 May 2013.

GPDRR (Global Platform for Disaster Risk Reduction). 2013b. Highlevel dialogue communiqué ahead of the wave: Leading the way to resilience. Fourth session of the global platform for disaster risk reduction. Geneva. http://www.preventionweb.net/files/33281_ highlevelcommunique.pdf. Accessed 21-23 May 2013.

Hewitt, K. 1983. Interpretations of calamity: From the viewpoint of human ecology. Winchester: Allen \& Unwin.

Hewitt, K. 1997. Regions of risk-A geographical introduction to disasters. Harlow: Addison Wesley Longman.

Hinkel, J. 2011. Indicators of vulnerability and adaptive capacity: Towards a clarification of the science-policy interface. Global Environmental Change: Human and Policy Dimensions 21(1): 198-208.

Holling, C.S. 1973. Resilience and stability of ecological systems. Annual Review of Ecology and Systematics 4: 1-23.

Hufschmidt, G. 2011. A comparative analysis of several vulnerability concepts. Natural Hazards 58(2): 621-643.

IFRC (International Federation of Red Cross and Red Crescent Societies). 2012. The long road to resilience. Impact and costbenefit analysis of DRR in Bangladesh. Geneva: IFRC.

Ionescu, C., R.J.T. Klein, J. Hinkel, K.S.K. Kumar, and R. Klein. 2009. Towards a formal framework of vulnerability to climate change. Environmental Modeling and Assessment 14(1): 1-16.

KatNet (Katastrophennetzwerk). 2012. Resilience and vulnerability What is the usage of these concepts for disaster management?" Conference, 14-16 November 2012, University of Bonn, Bonn. http://www.katastrophennetz.de/index.php/de/resilienz2012 (in German). Accessed 18 March 2014.

Klein, R.J.T. 2004. Resilience to natural hazards: How useful is this concept? In EVA Working Paper No. 9, DINAS-COAST Working Paper No. 14. Potsdam, Germany: Potsdam Institute for Climate Impact Research.

Klein, R.J.T. 2009. Identifying countries that are particularly vulnerable to the adverse effects of climate change: An academic or a political challenge? Carbon and Climate Law Review 3(3): 284-291.

Klein, R.J.T., R.J. Nicholls, and F. Thomalla. 2003. Resilience to natural hazards: How useful is this concept? Global Environmental Change Part B 5(1-2): 35-45.

Kuhlicke, C. 2013. Resilience: A capacity and a myth: Findings from an in-depth case study in disaster management research. Natural Hazards 67(1): 61-76.

Lewis, J., and I. Kelman. 2010. Places, people and perpetuity: Community capacities in ecologies of catastrophe. ACME: An International E-Journal for Critical Geographies 9(2): 191-220.

Lorenz, D.F. 2013. The diversity of resilience: Contributions from a social science perspective. Natural Hazards 67(1): 7-24.

Manyena, S.B. 2006. The concept of resilience revisited. Disasters 30(4): 434-450.

Menoni, S., D. Molinari, D. Parker, F. Ballio, and S. Tapsell. 2012. Assessing multifaceted vulnerability and resilience in order to design risk-mitigation strategies. Natural Hazards 64(3): 2057-2082.

Miller, F., H. Osbahr, E. Boyd, F. Thomalla, S. Bharwani, G. Ziervogel, B. Walker, J. Birkmann, et al. 2010. Resilience and vulnerability: Complementary or conflicting concepts? Ecology and Society 15(3): Article 11.
Mitchell, K. 1990. Human dimensions of environmental hazards. In Nothing to fear, ed. A. Kirby, 131-175. Tuscon: University of Arizona Press.

Mustafa, D., S. Ahmed, E. Saroch, and H. Bell. 2011. Pinning down vulnerability: From narratives to numbers. Disasters 35(1): 62-86.

Norris, F., S. Stevens, B. Pfefferbaum, K. Wyche, and R. Pfefferbaum. 2008. Community resilience as a metaphor, theory, set of capacities and strategy for disaster. American Journal of Community Psychology 41(1): 127-150.

OECD (Organisation for Economic Co-operation and Development). 2013. What does resilience mean for donors? OECD factsheet. http://www.oecd.org/dac/governance-development/risk-resilience. htm. Accessed 18 March 2014.

Oliver-Smith, A. 1991. Success and failures in post-disaster resettlement. Disasters 15(1): 12-23.

Oliver-Smith, A. 1994. Peru's five hundred year earthquake: Vulnerability in historical context. In Disasters, development and environment, ed. A. Varley, 31-48. Chichester: John Wiley and Sons.

Oliver-Smith, A. 2002. Theorizing disasters-Nature, power and culture. In Catastrophe and culture-The anthropology of disaster, ed. S.M. Hoffman, and A. Oliver-Smith, 23-47. Santa Fe: School of American Research Press.

Omand, D. 2013. Building national resilience and crisis management capabilities. Paper presented at the 3rd annual conference of the Institute for risk and disaster reduction, June 2013, University College London, London.

Perrow, C. 1984. Normal accidents: Living with high-risk technologies. New York: Basic Books.

Park, J., T.P. Seager, P.S.C. Rao, M. Convertino, and I. Linkov. 2013. Integrating risk and resilience approaches to catastrophe management in engineering systems. Risk Analysis 33(3): 356-367.

Renn, O., and F. Keil. 2008. Approaching systemic risks (Systemische Risiken. Versuch einer Charakterisierung). GAIA 17(4): 349-354.

Renn, O., and F. Keil. 2009. What is systemic about systemic risks? (Was ist das Systemische an Systemischen Risiken?). GAIA 18(2): 97-99.

Renn, O., P.-J. Schweizer, M. Dreyer, and A. Klimke. 2007. Risk: How society handles uncertainty (Risiko: Über den gesellschaftlichen Umgang mit Unsicherheit). Munich: Oekom Verlag.

SFC (Swiss Federal Council). 2012a. Strategy for civil protection 2015+ (Strategie Bevölkerungsschutz und Zivilschutz, 2015+). Bern: SFC (in German).

SFC (Swiss Federal Council). 2012b. National strategy for protecting critical infrastructure (Nationale Strategie zum Schutz kritischer Infrastrukturen). Bern: SFC (in German).

SFOCP (Swiss federal office for civil protection). 1995. Guideline KATANOS-Catastrophes and emergencies in Switzerland. A comparative overview (Leitfaden KATANOS_Katastrophen und Notlagen in der Schweiz. Eine vergleichende Übersicht). Bern: SFOCP (in German).

SFOCP (Swiss federal office for civil protection). 2003. Guideline KATARISK - Catastrophes and emergencies in Switzerland. A risk analysis from the perspective of civil Protection (Leitfaden KATARISK-Katastrophen und Notlagen in der Schweiz. Eine Risikobeurteilung aus Sicht des Bevölkerungsschutzes). Bern: SFOCP (in German).

SFOCP (Swiss federal office for civil protection). 2013. Guideline KATAPLAN-Cantonal risk analysis and prevention (Leitfaden KATAPLAN-Kantonale Gefährdungsanalyse und Vorsorge). Bern: SFOCP (in German).

Star, S.L., and J.R. Griesemer. 1989. Institutional ecology, "translations" and boundary objects: Amateurs and professionals in Berkeley's museum of vertebrate zoology, 1907-39. Social Studies of Science 19(3): 387-420. 
Strunz, S. 2012. Is conceptual vagueness an asset? Arguments from philosophy of science applied to the concept of resilience. Ecological Economics 76: 112-118.

Turner, B.L., R.E. Kasperson, P.A. Matson, J.J. McCarthy, R.W. Corell, L. Christensen, N. Eckley, J.X. Kasperson, et al. 2003. A framework for vulnerability analysis in sustainability science. Proceedings of the National Academy of Sciences of the United States of America 100(14): 8074-8079.

UKCO (United Kingdom, Cabinet Office). 2013. National risk register of civil emergencies (NRR). Cabinet Office UK. https://www.gov.uk/government/publications/national-risk-regis ter-for-civil-emergencies-2013-edition.

UKG (United Kingdom, Government of). 2004. Civil Contingencies Act. http://www.legislation.gov.uk/ukpga/2004/36. Accessed 18 March 2014.

UKG (United Kingdom, Government of). 2010. National Security Strategy. Command 7953. https://www.gov.uk/government/up loads/system/uploads/attachment_data/file/61936/national-securitystrategy.pdf.

UN (United Nations). 1987. International Decade for Natural Disaster Reduction. A/RES/42/169. http://www.un.org/docu ments/ga/res/42/a42r169.htm. Accessed 18 March 2014.

UN (United Nations). 1999. Activities of the International Decade for Natural Disaster Reduction. Report of the Secretary-General. A/54/132E/1999/80. http://www.un.org/esa/documents/ecosoc/ docs/1999/e1999-80.htm. Accessed 18 March 2014.

UN (United Nations). 2005. International Strategy for Disaster Reduction. A/RES/60/195. http://www.un.org/en/ga/search/view_ doc.asp?symbol=A/RES/60/195. Accessed 18 March 2014.

UNDRO (United Nations Disaster Relief Organization). 1982. Shelter after disaster. New York: UNDRO, United Nations.

UNISDR (United Nations International Strategy for Disaster Reduction). 2004. Living with risk. A global review of disaster reduction initiatives. Geneva: UNISDR.

UNISDR (United Nations International Strategy for Disaster Reduction). 2005. Hyogo framework for action 2005-2015. Building the resilience of nations and communities to disasters. Extract from the final report of the world conference on disaster reduction (A/CONF.206/6). Geneva: UNISDR.

UNISDR (United Nations International Strategy for Disaster Reduction). 2010-2011. Hyogo framework for action 2005-2015. Midterm review. Geneva: UNISDR.

UNISDR (United Nations International Strategy for Disaster Reduction). 2012. Towards a post-2015 framework for disaster risk reduction. Geneva: UNISDR.

UNISDR (United Nations International Strategy for Disaster Reduction). 2013. Implementation of the Hyogo framework for action. Summary of reports 2007-2013. Geneva: UNISDR.

Vetter, A., and I. Schauser. 2013. Adaptation to climate change (Anpassung an den Klimawandel). GAIA 22(4): 248-254 (in German).

Vogel, C., S.C. Moser, R.E. Kasperson, and G.D. Dabelko. 2007. Linking vulnerability, adaptation, and resilience science to practice: Pathways, players, and partnerships. Global Environmental Change 17(3-4): 349-364.

Watts, M.J., and H.G. Bohle. 1993. The space of vulnerability: The causal structure of hunger and famine. Progress in Human Geography 17(1): 43-67.

Weick, K.E., and K.M. Sutcliffe. 2007. Managing the unexpected: Resilient performance in an age of uncertainty. San Francisco: Jossey-Bass.

White, G.F., R.W. Kates, and I. Burton. 2001. Knowing better and losing even more: The use of knowledge in hazards management. Environmental Hazards 3(3): 81-92.

Wisner, B. 1993. Disaster vulnerability: Scale, power and daily life. GeoJournal 30(2): 127-140.

Wisner, B., P. Blaikie, T. Cannon, and I. Davis. 2004. At riskNatural hazards, people's vulnerability and disasters, 2nd ed. London: Routledge.

Zhou, H.J., J.A. Wang, J.H. Wan, and H.C. Jia. 2010. Resilience to natural hazards: A geographic perspective. Natural Hazards 53(1): 21-41.

Zolli, A., and A.M. Healy. 2012. Resilience: Why things bounce back. New York: Free Press. 